Available online at http://journal.stkip-andi-matappa.ac.id/index.php/histogram/index

Histogram : Jurnal Pendidikan Matematika 2 (2), 2018, 159-168

\title{
EFEKTIFITAS MODEL PEMBELAJARAN BASED LEARNING PADA PENINGKATAN KEMAMPUAN PEMECAHAN MASALAH SISWA
}

\author{
Sri Yulianti \\ Universitas Islam Ogan Komering Ilir (UNISKI) Kayuagung \\ * Corresponding Author. Email: sriyulianti82@gmail.com \\ Received: 12 August 2018; Revised: 21 September 2018; Accepted: 27 September 2018
}

\section{ABSTRAK}

Penelitian ini bertujuan untuk mengetahui pengaruh model Problem Based Learning terhadap kemampuan pemecahan masalah siswa pada pembelajaran matematika kelas X di SMA Bait AlQuran Kayuagung Ogan Komering Ilir Sumatera Selatan. Metode penelitian yang digunakan adalah quasi eksperiment dengan rancangan non-equivalent control group design. Sampel penelitian ini adalah kelas X Palestina sebagai kelas eksperimen dan kelas X Yaman sebagai kelas kontrol. Sampel penelitian ini dipilih dengan teknik purposive sampling. Proses pembelajaran di kelas eksperimen mendapatkan perlakuan dengan model pembelajaran Problem Based Learning dan di kelas kontrol diajarkan dengan model pembelajaran konvensional. Pengumpulan data menggunakan teknik tes berbentuk soal essai berjumlah lima soal untuk mengukur kemampuan pemecahan masalah siswa. Berdasarkan uji hipotesis dengan menggunakan uji-t pada taraf signifikan $(\alpha)=0,05$. Berdasarkan analisis t-test data test akhir diperoleh nilai Sig. (2-tailed) sebesar 0,00 < 0,05 kemudian menurut basis pengambilan keputusan dalam T-Test dapat disimpulkan $\mathrm{H}_{0}$ ditolak dan Ha diterima. Dengan demikian hipotesis yang diajukan dalam penelitian ini terbukti, bahwa ada pengaruh yang signifikan model PBL pada kemampuan pemecahan masalah matematika siswa kelas X SMA Bait Al-Quran Kayuagung.

Kata kunci: pembelajaran matematika, based learning, pemecahan masalah

How to Cite: Yulianti, S. (2018). Efektifitas Model Pembelajaran Based Learning Pada Peningkatan Kemampuan Pemecahan Masalah Siswa. Histogram: Jurnal Pendidikan Matematika, 2(2), 159-168. doi: http://dx.doi.org/10.31100/histogram.v2i2.214

Permalink/DOI:

http://dx.doi.org/10.31100/histogram.v2i2.214

\section{PENDAHULUAN}

Pendidikan pada dasarnya adalah interaksi antara guru dan siswa yang terjadi dalam situasi yang kondusif untuk pelaksanaan pendidikan, baik di sekolah maupun di luar sekolah. Pendidikan tidak hanya bertujuan untuk memberikan materi pelajaran tetapi lebih menekankan bagaimana mengajak siswa untuk menemukan dan membangun pengetahuan mereka sendiri sehingga siswa dapat mengembangkan kecakapan hidup (life skill) dan siap memecahkan masalah yang dihadapi dalam kehidupan.

Matematika adalah ilmu dasar yang berkembang sangat cepat baik materi maupun kegunaannya. Matematika adalah salah satu pelajaran di sekolah yang dianggap cukup

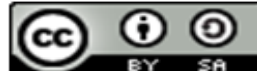




\section{Histogram: Jurnal Pendidikan Matematika, 2 (2), 2018 - 160 Sri Yulianti}

berperan penting. Kurikulum matematika sekolah yang terintegrasi akan dapat memberikan pengalaman belajar yang lengkap dan bermakna. Tetapi banyak siswa mengalami kesulitan dalam belajar matematika, terutama dalam memahami konsep yang merupakan pemahaman dasar yang harus dikuasai siswa untuk memecahkan masalah, sehingga kemampuan kognitif siswa antara pemahaman dan tingkat kemampuan pemecahan masalah tidak seimbang (Effendi, 2010). Kebanyakan orang memandang matematika sebagai studi yang paling sulit, namun semua orang harus mempelajarinya karena itu adalah sarana untuk menyelesaikan masalah kehidupan sehari-hari yang berarti bahwa kursus matematika dapat digunakan sebagai sarana untuk mengembangkan kemampuan siswa. Kemampuan ini bisa menjadi kemampuan pemecahan masalah matematika (GusDur, 2012).

Menurut John Dewey proses belajar hanya akan terjadi kalau siswa dihadapkan kepada masalah dari kehidupan nyata untuk di pecahkan. Dalam membahas dan menjawab masalah, siswa harus terlibat dalam kegiatan nyata, misalnya mengobservasi, mengumpulkan data dan menganalisisnya bersama - sama kawan - kawan yang lain dalam kelompok atau di kelasnya (Haris Mujiman, 2008:54). Pembelajaran di kelas akan berhasil apabila siswa menguasai keterampilan-keterampilan kooperatif yang antara lain adalah keterampilan menyampaikan ide-ide, presentasi di depan teman satu kelompok maupun presentasi di depan teman satu kelas, mengkritik ide-ide maupun keterampilan bekerjasama dengan teman lain kemudian siswa terlatih memiliki kemampuan keterampilan kooperatif sehingga lebih banyak mendapatkan informasi dari teman-teman yang lain.

Ada empat jenis kesulitan siswa dalam memecahkan masalah matematika, pertama memahami masalah yang diberikan, baik mendefinisikan strategi solusi yang tepat, yang ketiga membuat kalimat matematika, dan yang keempat melakukan prosedur matematika yang benar. Untuk membantu siswa keluar dari kesulitan salah satunya adalah menggunakan model pembelajaran yang menempatkan keaktifan siswa dalam berpikir (Sari, 2011). Siswa kurang didorong untuk mengembangkan kemampuan berpikir menjadi salah satu masalah dalam pendidikan ( Sanjaya, 2011).

Berdasarkan hasil observasi yang penulis lakukan selama penelitian yang dilakukan di kelas X SMA Bait Al-Quran Kayuagung diketahui bahwa model pembelajaran yang digunakan adalah model konvensional yang hanya didominasi oleh guru sebagai sumber pengetahuan sehingga tingkat siswa 'pemahaman materi ajar dan keterampilan 
pemecahan masalah siswa matematika menjadi kurang optimal dan siswa menjadi kurang aktif.

Salah satu langkah yang dapat digunakan untuk meningkatkan kemampuan pemecahan masalah matematika adalah dengan pemilihan dan penggunaan model pembelajaran yang tepat sehingga siswa dapat mengoptimalkan kemampuan berpikir melalui proses pemecahan masalah. Pemecahan masalah adalah proses menemukan masalah yang dihadapi dalam bentuk aturan baru yang lebih tinggi dan keterampilan intelektual tingkat tinggi dapat dikembangkan melalui pemecahan masalah (Sumiati dan Asra, 2009; Suherman 2001).

Pembelajaran berbasis masalah dapat didefinisikan sebagai serangkaian kegiatan pembelajaran yang menekankan proses pemecahan masalah yang merupakan pendekatan pembelajaran yang menggunakan masalah dunia nyata sebagai konteks esensi pembelajaran dan merupakan instruksi yang menantang siswa untuk belajar untuk belajar (Gunantara, 2014). Ada empat langkah dari model pembelajaran PBL, yang pertama untuk mengatur siswa pada masalah, yang kedua untuk mengatur siswa untuk belajar, tiga penuntun penyelidikan individu dan kelompok, terakhir mengembangkan dan mempresentasikan pekerjaan (Amir, 2009; Hosnan , 2014).

Berdasarkan latar belakang yang telah disebutkan di atas maka rumusan masalah dalam penelitian ini adalah "Bagaimana efektifitas Problem Based Learning terhadap kemampuan pemecahan masalah siswa dalam pembelajaran matematika kelas X di SMA Bait Al-Quran Kayuagung" 


\section{METODE PENELITIAN}

\section{A. Tempat dan Waktu Penelitian}

Penelitian ini dilaksanakan di SMA Bait Al-Quran Kabupaten Ogan Komering Ilir Sumatera Selatan pada semester genap tahun ajaran 2017/2018. Waktu pelaksanaan penelitian pada 5 Februari sampai dengan 22 Maret 2018.

\section{B. Instrumen Penelitian}

Dalam penelitian ini, instrumen yang digunakan adalah tes tertulis yang berbentuk esai yaitu siswa akan menyelesaikan soal yang berbasis problem based learning (PBL).

\section{Teknik Pengumpulan Data}

Dalam penelitian ini, data dikumpulkan dengan menggunakan tes tertulis. Sebelum tes awal diberikan pada kelas eksperimen dan kelas kontrol, tes terlebih dahulu diujicobakan kepada kelas yang bukan menjadi sampel untuk mengetahui tingkat validitas dan reliabilitas tes. Setelah uji coba, tes awal dilakukan sebelum pelajaran di kelas eksperimen dan kelas kontrol berlangsung, dengan tujuan untuk mengetahui kemampuan siswa dari kedua kelas tersebut pada materi persamaan kuadrat.

Setelah tes awal, kelas eksperimen diberikan perlakuan selama 8 kali pertemuan dengan menggunakan model pembelajaran problem based learning (PBL), sedangkan kelas kontrol tidak diberikan perlakuan. Setelah diberikan perlakuan terhadap kelas eksperimen, maka siswa diberikan postes yaitu soal esai berjumlah lima soal, dengan tujuan untuk mengukur tingkat keberhasilan siswa setelah mendapatkan perlakuan.

\section{Teknik Analisis Data}

Setelah data yang diperlukan berhasil dikumpulkan, baik dari kelas eksperimen maupun kelas kontrol, data tersebut dianalisis. Untuk melihat pengaruh PBL, digunakan uji-t. Uji t terdiri atas paired sample t-test dan independent sample t-test. Paired sample ttest digunakan untuk mengukur kemampuan siswa dalam kelompok ketika sebelum dan sesudah diberikan perlakuan, sedangkan independent sample t-test digunakan untuk mengukur tingkat kemampuan siswa antar kelompok eksperimen dan kontrol, dimana yang dibandingkan adalah nilai posttes. 
Histogram: Jurnal Pendidikan Matematika, 2 (2), 2018 - 163

Sri Yulianti

\section{HASIL DAN PEMBAHASAN}

Tabel 1. Hasil pre-test dan post-test kelas eksperimen dan kelas kontrol

\begin{tabular}{ccc}
\hline Kelas & $\begin{array}{c}\text { Rerata Data } \\
\text { Pre-test }\end{array}$ & $\begin{array}{c}\text { Rerata Data } \\
\text { Post-test }\end{array}$ \\
\hline Eksperimen & 44,04 & 74,67 \\
Kontrol & 44,375 & 58,00
\end{tabular}

Sumber: Data Primer, Tahun: 2018

Berdasarkan tabel 1, data tes awal diperoleh skor rata-rata kemampuan awal kelas eksperimen 44,04 dan skor rata-rata kelas kontrol 44,375 sehingga secara deskriptif dapat disimpulkan bahwa kemampuan awal siswa antar kelas eksperimen dan kelas kontrol sebelum diberikan perlakuan menggunakan model PBL hampir sama tetapi pada data tes akhir diperoleh skor rata-rata kemampuan pemecahan masalah akhir kelas eksperimen 74,67 dan skor rata-rata kelas kontrol 58,00. Sehingga secara deskriptif dapat disimpulkan bahwa tingkat kemampuan pemecahan masalah pada tes akhir kelas eksperimen setelah diterapkannya model PBL lebih tinggi dari kelas kontrol yang mendapatkan perlakuan menggunakan model pembelajaran konvensional. 
Histogram: Jurnal Pendidikan Matematika, 2 (2), 2018 - 164

Sri Yulianti

Tabel 2. Hasil Uji-t sampel pretest kelas Eksperimen dan pretest kelas Kontrol

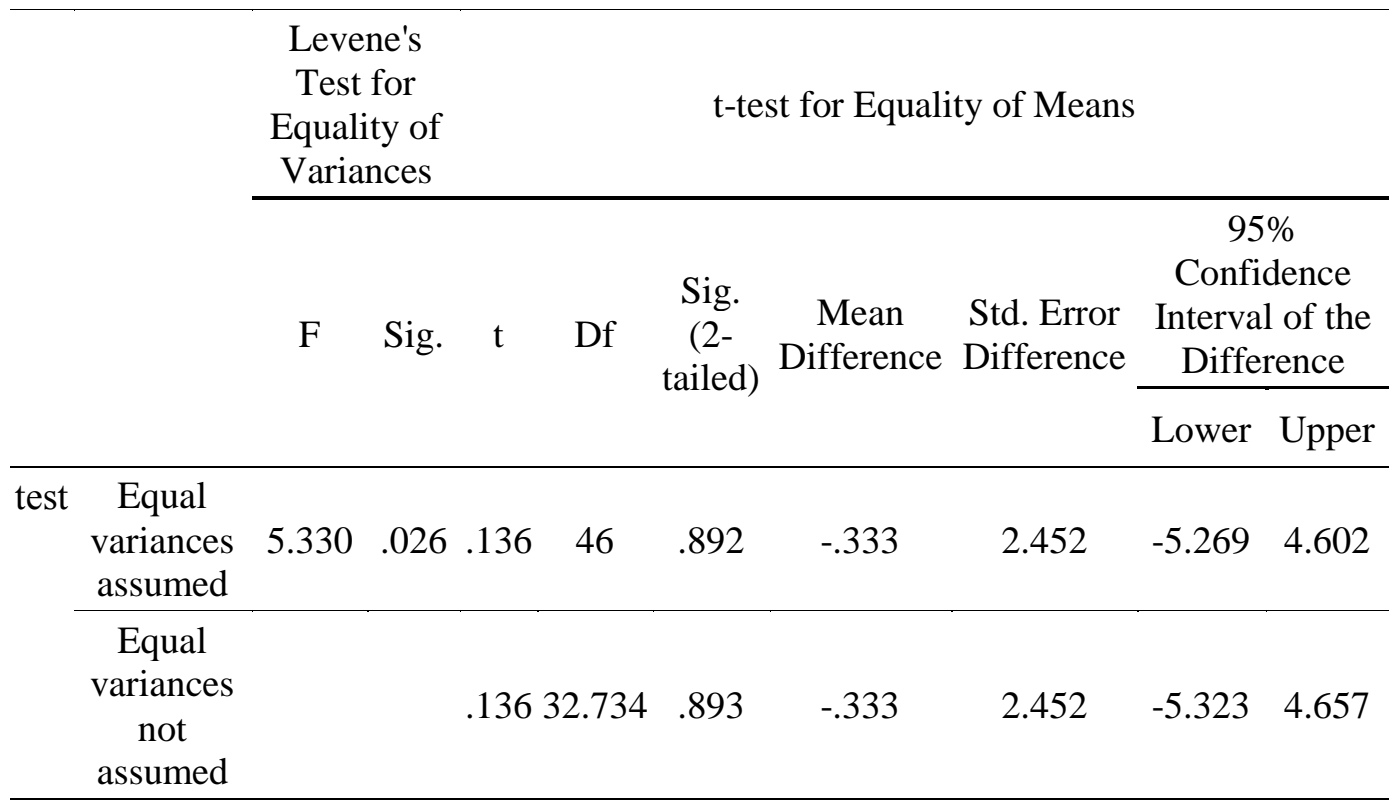

(Sumber : Data Primer, Tahun: 2018)

Begitupun dengan analisis uji-t dalam hal ini peneliti menggunakan SPSS 16 untuk data tes awal seperti dilihat pada Tabel 2 yaitu diperoleh nilai Sig.(2-tailed) sebesar 0,892 $>0,05$, maka sesuai dasar pengambilan keputusan dalam Uji Independent Sample T-Test, maka dapat disimpulkan $\mathrm{H}_{0}$ diterima. Dengan demikian tidak ada perbedaan yang signifikan rata-rata kemampuan pemecahan masalah matematika siswa baik pada kelas eksperimen dan kelas kontrol. 
Histogram: Jurnal Pendidikan Matematika, 2 (2), 2018 - 165

Sri Yulianti

Tabel 3. Hasil Uji-t sampel postest kelas Eksperimen dan postest kelas Kontrol

\begin{tabular}{|c|c|c|c|c|c|c|c|}
\hline & \multicolumn{7}{|c|}{$\begin{array}{l}\text { Levene's } \\
\text { Test for } \\
\text { Equality of t-test for Equality of Means } \\
\text { Variances }\end{array}$} \\
\hline & \multirow[t]{2}{*}{ Sig. } & \multirow[t]{2}{*}{$\mathrm{t}$} & \multirow[t]{2}{*}{ Df } & \multirow[t]{2}{*}{$\begin{array}{l}\text { Sig. } \\
(2- \\
\text { tailed) }\end{array}$} & \multirow[t]{2}{*}{$\begin{array}{c}\text { Mean } \\
\text { Difference }\end{array}$} & \multirow[t]{2}{*}{$\begin{array}{l}\text { Std. Error } \\
\text { Difference }\end{array}$} & $\begin{array}{c}95 \% \\
\text { Confidence } \\
\text { Interval of the } \\
\text { Difference } \\
\end{array}$ \\
\hline & & & & & & & Lower Upper \\
\hline $\begin{array}{l}\text { Equal } \\
\text { variances } \\
\text { assumed } \\
\end{array}$ & 10.724 .002 & 8.486 & 46 & .000 & 16.667 & 1.964 & 12.71320 .620 \\
\hline $\begin{array}{l}\text { test Equal } \\
\text { variances } \\
\text { not } \\
\text { assumed }\end{array}$ & & 8.486 & 31.363 & .000 & 16.667 & 1.964 & 12.66320 .670 \\
\hline
\end{tabular}

(Sumber : Data Primer, Tahun: 2018)

Pada tabel 3 diatas dapat dilihat bahwa nilai tes akhir atau postest diperoleh nilai Sig.(2-tailed) sebesar $0,00<0,05$ maka dapat disimpulkan $\mathrm{H}_{0}$ ditolak dan $\mathrm{H}_{\mathrm{a}}$ diterima yaitu terdapat perpedaan yang signifikan kemampuan pemecahan masalah matematika siswa kelas X SMA Bait Al-Quran Kayuagung setelah mendapatkan perlakuan model pembelajaran Problem Based Learning. 


\section{KESIMPULAN DAN SARAN}

\section{A. Kesimpulan}

Berdasarkan hasil penelitian dan pembahasan yang telah dikemukakan di atas maka dapat dilihat bahwa terdapat perbedaan yang signifikan model pembelajaran Problem Based Learning terhadap kemampuan pemecahan masalah matematika siswa kelas X SMA Bait Al-Quran Kayuagung dengan skor rata-rata 74.67 dilihat dari hasil belajar, sehingga dapat disimpulkan bahwa model pembelajaran problem based learning lebih efektif untuk meningkatkan kemampuan pemecahan masalah matematika pada pembelajaran persamaan kuadrat.

\section{B. Saran}

Berdasarkan penelitian yang telah dilakukan, disarankan untuk melakukan perbaikan dalam pelaksanaan pembelajaran, perlunya pengelolaan kelas dengan terencana dan terorganisir serta disiplin menggunakan waktu yang telah dialokasikan, misalnya memberikan batasan waktu saat mengerjakan soal dan diskusi agar tahapan pembelajaran matematika dengan model problem based learning ini dapat terlaksana dengan baik. 
Histogram: Jurnal Pendidikan Matematika, 2 (2), 2018 - 167

Sri Yulianti

\section{DAFTAR PUSTAKA}

Effendi, M, M. (2010). Prinsip Kurikulum Matematika Sekolah: Pengembangan Tinjauan Orientasi. Skripsi. FKIP: Universitas Muhammadiyah Malang.

Gunantara. (2014). Penerapan Model Pembelajaran Berbasis Masalah Untuk Meningkatkan Matematika Siswa Keterampilan Pemecahan Masalah. Jurnal Mimbar PGSD Ganesha University of PGSD Department

Hosnan, M. (2014). Pendekatan Ilmiah Dan Kontekstual Adalah Waktu Yang Lama Dari Abad Ke-2 Belajar. Bogor: Graha Indonesia.

Sanjaya, W. (2011). Strategi Pembelajaran Berorientasi Standar Proses Pendidikan. Jakarta: Kencana.

Sari, M, K. (2011). Profil Kesulitan Siswa Kelas Viii Dalam Pemecahan Masalah Matematika Pada Pokok Bahasan Sistem Persamaan Linear Dua Variabel. Malang : FKIP Universitas Sebelas Maret

Suherman, E. (2001). Strategi Buku Teks Umum Matematika Kontemporer Belajar. Bandung: JICA-Universitas Pendidikan Indonesia

Sumiati dan Asra. (2009). Metode Pembelajaran. Bandung: Wacana Prima

Taufiq, A. (2009). Inovasi Pendidikan Melalui Pembelajaran Berbasis Masalah. Jakarta: Kencana 
Histogram: Jurnal Pendidikan Matematika, 2 (2), 2018 - 168

Sri Yulianti

\section{UCAPAN TERIMA KASIH}

Ucapan terima kasih yang penulis sampaikan kepada kepala sekolah SMA Bait Al-Quran dan guru mata pelajaran matematika SMA Bait Al-Quran Kayuagung Sumatera Selatan yang telah memberikan izin dan dukungan kepada peneliti untuk melaksanakan penelitian tentang "Effektifitas model Pembelajaran Problem Based Learning terhadap pemecahan masalah siswa pada pembelajaran matematika kelas X di SMA Bait Al-Quran" TA 2017/2018, semoga hasil penelitian ini dapat menjadi referensi bagi guru dalam kegiatan belajar dan mengajar, terutama pada mata pelajaran matematika. 